\title{
Múltiplos Equilíbrios*
}

\author{
Multiple Balances
}

PERSIO ARIDA**

RESUMO: Essa é a segunda nota de uma série de quatro notas escritas para estudantes nos debates sobre políticas atuais. Ela se concentra em um modelo simples de economia aberta, no qual existe uma probabilidade subjetiva de inadimplência na dívida interna. Sob certas condições, há mais de um par de juros/câmbio consistente com uma determinada meta de inflação. A dinâmica é explorada sob uma regra de comportamento simples, segundo a qual o Banco Central aumenta os juros se a inflação estiver acima da meta. São discutidos os efeitos do aperto fiscal, choques externos nas taxas de juros ou dívida soberana e mudanças esperadas no regime de conversibilidade.

PALAVRAS-CHAVE: Taxa de juros; duplo equilíbrio; conversibilidade; risco soberano.

ABSTRACT: The note is the second of a series of four notes written for students on current policy debates. It focuses on a simple open economy model in which there is a subjective default probability on domestic debt. Under certain conditions there is more than one pair interest/exchange consistent with a given inflation target. Dynamics is explored under a simple behavior rule according to which Central Bank increases interest if inflation is above target. The effect of credible fiscal tightening, external shocks in interest rates or sovereign debt and expected changes in the convertibility regime are discussed.

KEYWORDS: Interest rate; double balance; convertibility; sovereign risk.

JEL Classification: E43.

Esta é a segunda de uma série de quatro notas sobre a taxa de juros no Brasil. A série tem por objetivo ajudar estudantes a compreender temas presentes no dia a dia das discussões sobre política monetária. Seu caráter é exclusivamente ilustrativo e didático; em várias instâncias preferi sacrificar o rigor formal em favor da

\footnotetext{
* O texto original, intitulado "default risk and interest rates: an expository note" foi escrito em fevereiro 2002. Traduzido e revisado em maio 2002. Agradeço comentários de Edmar Bacha, Alexandre Schwartzman, Francisco Lopes e os integrantes de seminários no IBMEC e na FGV.

* Foi presidente do Banco Central do Brasil. Economista autônomo, São Paulo-SP, Brasil. E-mail: aridap@gmail.com.
} 
intuição. Não há nenhuma mensuração empírica dos efeitos aqui discutidos. Ilações sobre políticas econômicas são assim despropositadas.

A primeira nota apresentou o modelo básico do regime de metas e considerou o efeito da presença de ativos financeiros indexados à taxa de juros. Nesta nota a análise se desloca para uma economia aberta na qual há risco de default na dívida pública. A questão que orienta a exposição é saber em que condições pode existir mais de um equilíbrio e quais seriam suas propriedades.

A segunda nota está organizada da seguinte forma. A seção I apresenta o modelo. A seção II ilustra a possibilidade de existência de um equilíbrio ruim (juros mais altos e moeda mais depreciada). A seção III considera a dinâmica gerada por uma norma de atuação do Banco Central que consiste em aumentar a taxa de juros sempre que a inflação supera a meta e vice-versa. A seção IV conclui a nota examinando o efeito de variações na taxa de juros fixada pelo Federal Reserve, na política fiscal, nos condicionantes exógenos do risco soberano e na percepção de restrições à conversibilidade da moeda. A seção $\mathrm{V}$ conclui apontando o objeto da terceira nota da série.

\section{O MODELO}

O modelo é formado pelas equações (1), (2) e (3). A primeira equação é umaforma reduzida do sistema de metas inflacionárias em uma economia aberta.

$$
\pi^{*}=\pi(\mathrm{R}, \mathrm{E})
$$

Em (1), $\pi^{*}$ é a meta anunciada pelo Banco Central para o período em curso. $\mathrm{O}$ lado direito de (1) mostra a inflação em função da taxa real de juros $\mathrm{R}$ e da taxa de câmbio (captada através de E). A formulação é singela e deixa de lado choques de oferta ou demanda assim como defasagens temporais. Comento a seguir a razão de ser dessas duas variáveis como determinantes da taxa de inflação.

Noto inicialmente que $\mathrm{R}$ é a taxa real de juros enquanto a política monetária determina a taxa nominal de juros. O efeito da taxa nominal depende, evidentemente, do processo de formação de expectativas dos agentes sobre a evolução dos preços no período. Em alguns casos, exemplificados no Apêndice, uma variação na taxa nominal de juros equivale a uma variação na taxa real ex-ante de juros e torna-se razoável tratar a taxa real como uma variável de controle do Banco Central. Assim será feito nesta nota. A taxa real R, o único instrumento de política, afeta a inflação em (1) através de seu efeito sobre a demanda agregada: quanto maior a taxa real de juros, menor a demanda e menor a inflação.

A variável $\mathrm{E}$ é um número puro: a razão entre a taxa de câmbio nominal de longo prazo, $Z(f)$ e a taxa de câmbio do período em curso, denominada $Z(0)$. Ou seja, $E=Z(f) / Z(0)$. Capta-se através de $E$ o impacto do câmbio sobre a inflação no período em curso. Quanto menor E, maior a desvalorização da moeda no período e portanto, tudo o mais constante, maior a inflação. A curva (1) é negativamente inclinada no plano $(\mathrm{R}, \mathrm{E})$. 
A segunda equação reflete o equilíbrio no mercado de ativos. Há dois ativos apenas: dívida pública denominada em reais, emitida pelo Tesouro Brasileiro, e dívida pública denominada em dólares, emitida pelo Tesouro Norte-Americano. Os detentores de riqueza estão certos de que a taxa de câmbio $Z(0)$ reverterá ao valor de longo prazo $Z(f)$ ao final do período. A taxa de juros fixada pelo Federal Reserve é $\mathrm{R}^{\mathrm{US}}$ enquanto $\lambda$ é a probabilidade subjetiva de default na dívida pública emitida pelo Tesouro Brasileiro.

$$
(1+\mathrm{R}) \cdot(1-\lambda)=\left(1+\mathrm{R}^{\mathrm{US}}\right) \cdot \mathrm{E}
$$

(2) significa que o retorno esperado de um real investido no Brasil deve ser igual ao retorno esperado de um real dividido pela taxa de câmbio de curto prazo $Z(0)$, investido no exterior e reconvertido em reais pela taxa de câmbio de longo prazo $\mathrm{Z}(\mathrm{f})$. O lado direito de (2) é um valor determinado, enquanto o lado esquerdo é um valor esperado; para que os investidores fiquem indiferentes entre as duas alternativas é necessário supor, como aqui faço, neutralidade em relação ao risco. Ignoro em (2) custos de transação na arbitragem internacional de taxas de juros.

A caracterização de default implícita em (2) é radical: ao final do período a dívida interna ou será integralmente paga, o principal ou os encargos, ou será repudiada e terá valor zero. É bem verdade que por default usualmente se designa uma vasta gama de eventos intermediários entre os extremos aqui postos (exemplos: recompra compulsória a preços discricionários, retenção de liquidez, pagamento parcial, alongamento compulsório, imposição de desconto, etc.) cujo efeito é, de uma ou outra forma, impor perdas parciais aos detentores de dívida. Pouco se ganharia analiticamente, no entanto, introduzindo eventos intermediários no grau de generalidade que aqui se usa.

Resta caracterizar a probabilidade subjetiva de default. Em princípio, a probabilidade subjetiva de default depende (i) do estoque de dívida acumulado no passado, (ii) do superávit fiscal primário esperado para o período em curso e (iii) da taxa de juros fixada pelo Banco Central. Nesta nota, a incerteza sobre o default é circunscrita à política fiscal. Sendo $\mathrm{D}_{-1}$ o estoque de dívida prévio, os agentes sabem que para pagar a dívida é necessário que o superávit fiscal no período seja $(1+\mathrm{R}) . \mathrm{D}_{-1}$; a probabilidade de default depende da avaliação subjetiva da probabilidade do superávit ser igual ou maior do que este montante. Em (1), destaco o efeito da taxa real de juros sobre a probabilidade de default (quanto maior R, maior $\lambda$ ) e capto através do parâmetro $\Theta$ variações no estado de expectativas sobre a política fiscal. Uma política fiscal mais contracionista (um valor maior de $\Theta$ ) reduz a probabilidade de default para uma dada taxa de juros.

$$
\lambda=\lambda(\mathrm{R}, \Theta)
$$

O evento de default aqui referido é aquele tornado célebre por Keynes: o default que ocorre quando os segmentos ativos da sociedade se recusam a transferir uma parcela considerada excessiva de sua renda aos rentistas. A diferença para com o caso descrito por Keynes é que a perda de valor da dívida ocorre, não através de uma inflação inesperada corroendo o valor real de uma dívida fixa em termos nominais, mas sim pelo repúdio. 
A formatação temporal do modelo é simples. O Banco Central fixa a taxa de juros. Os agentes avaliam então a probabilidade de default e a taxa de câmbio decorre da arbitragem no mercado de ativos. O Banco Central é bem-sucedido quando o par (R, E) resultante da política monetária produzir a taxa de inflação desejada. Ao final do período os detentores de riqueza saberão se a dívida interna foi ou não quitada. ${ }^{1}$

\section{EQUILÍBRIOS MÚLTIPLOS}

Para ganhar perspectiva sobre o modelo é útil analisá-lo no plano (R, E). A curva AA, derivada da primeira equação, descreve o conjunto de pares câmbio e juros que geram a meta de inflação desejada. Quanto maior a taxa real de juros, mais depreciado pode estar o valor da moeda doméstica para uma dada taxa de inflação: a curva AA é negativamente inclinada. Quanto mais rigorosa ou apertada a meta de inflação, maior deve ser a taxa de juros para uma dada taxa de câmbio; a curva AA desloca-se para a direita diante de uma meta inflacionária mais ambiciosa.

Consideremos agora o equilíbrio no mercado de ativos. Quando sobe a taxa de juros, cresce também o risco de default. O que acontece em termos líquidos com a taxa de retorno em reais? Dois casos devem ser distinguidos. No caso normal, o efeito direto da taxa de juros domina o efeito default. Ou seja, o lado esquerdo de (2) cresce com a taxa de juros. Apesar do maior risco de default, a taxa de juros majorada é percebida como trazendo um aumento do retorno esperado do investimento em reais. Neste caso, a maior taxa de juros desvaloriza o câmbio (para aumentar a rentabilidade do investimento no exterior) e a curva BB, resultante da substituição de (3) em (2), torna-se positivamente inclinada no plano (R, E).

$\mathrm{O}$ caso anômalo ocorre quando o efeito default domina o efeito juros: umaumento na taxa de juros diminui a taxa de retorno esperada do investimento em reais porque o trade-off entre risco e retorno torna-se desfavorável. Por arbitragem no mercado de ativos, a maior taxa de juros aprecia a taxa de câmbio (reduzindo pari passu a taxa de retorno do investimento no exterior) e a curva BB passa a ser negativamente inclinada no plano $(\mathrm{R}, \mathrm{E}) .^{2}$

A analogia à curva de captação de um banco privado é útil nesta conexão. Taxas de juros ligeiramente acima do mercado são normalmente associadas a cap-

\footnotetext{
${ }^{1}$ Uma formulação mais rigorosa de (2) apresentaria a taxa de câmbio de final de período relevante para a arbitragem de ativos como uma média ponderada das taxas de câmbio esperadas com default e sem default. A razão é que a redução do valor da riqueza financeira privada impacta o preço de todos os ativos, inclusive o da moeda estrangeira. Deixo-a como exercício ao leitor.

${ }^{2}$ Há uma interpretação alternativa do caso anômalo que convém aqui registrar, posto que independe de considerações pertinentes ao risco de default. Parte do princípio de que a conta capital é mais importante do que a conta corrente na determinação dos fluxos financeiros. Menor taxa de juros significaria mais crescimento e portanto mais investimento direto, apreciando a moeda por conseqüência.
} 
tações substanciais; taxas de juros muito acima do mercado, no entanto, sinalizam a dominância do risco de default e são associadas a captação mais reduzida.

O gráfico I ilustra a possibilidade de existência de mais de um equilíbrio. A curva $\mathrm{BB}$ traduz o equilíbrio no mercado de ativos. Por analogia à captação de um banco privado, a curva $\mathrm{BB}$ comporta-se de forma normal para baixas taxas de juros e de forma anômala para altas taxas de juros. No seu ramo normal, aumentos na taxa de juros valorizam a moeda nacional; no seu segmento anômalo geram uma percepção de risco tão negativa que terminam por depreciar a moeda nacional.

Antes de passar à discussão da dinâmica, devo enfatizar que o formato aqui adotado das curvas AA e BB é meramente ilustrativo. No nível de generalização desta nota, não há necessariamente apenas dois equilíbrios e, dependendo dos parâmetros, pode até não haver equilíbrio algum, como no caso de uma meta de inflação excessivamente ambiciosa (curva AA à direita de BB para todo par juros e câmbio). Transcende o propósito desta nota diferenciar casos empiricamente relevantes daqueles apenas logicamente possíveis.

\section{DINÂMICA}

Qualquer ponto ao longo da curva BB é um equilíbrio de mercado, mas não necessariamente um equilíbrio do ponto de vista do Banco Central. Só o será quando o $\operatorname{par}(\mathrm{R}, \mathrm{E})$ gerar a inflação desejada. No gráfico I há dois pares juros e câmbio que atendem simultaneamente à condição de arbitragem de ativos e à função objetivo do Banco Central. O equilíbrio ruim ocorre no ramo anômalo da curva BB e é caracterizado por maior taxa de juros e moeda mais depreciada.

O Banco Central não conhece o formato das curvas AA ou BB. Fixada a taxade juros, a resposta de mercado será dada pelo valor de E ditado pela curva BB, e a inflação, pela substituição do par resultante em (1) (ou, graficamente, pela curva de iso-inflação que passa exatamente pelo par (R, E) em questão). Pratica assim um tâtonnement ao longo da curva BB em busca da inflação $\pi^{*}$, subindo a taxa de juros sempre que a inflação está acima da meta e vice-versa. Duas são as questões aqui relevantes: (a) seria tal norma de atuação suficiente para assegurar a convergência da inflação à meta? (b) caso sim, a convergência seria aquela do bom equilíbrio?

Para responder a estas questões, analisemos inicialmente o comportamento da inflação à medida em que o Banco Central aumenta as taxas de juros. No ramo normal da curva BB o efeito das políticas monetárias contracionistas é inambíguo: quanto maior a taxa real de juros, menor a inflação. A razão é evidente: quanto maior a taxa de juros, mais apreciada é a moeda e o efeito contracionista direto da política monetária é alavancado pela valorização cambial.

Diversa é a situação no ramo anômalo da curva BB. Um aumento na taxa de juros carrega consigo uma desvalorização da taxa de câmbio. $O$ efeito sobre a inflação é em princípio indeterminado: a inflação se reduz quando o efeito juros domina o efeito câmbio e vice-versa.

Consideremos agora a atuação do Banco Central. No ramo normal da curva 
BB ela é necessariamente bem-sucedida. Taxas de juros acima de $\mathrm{R}_{1}$ provocam inflações abaixo da meta porque a taxa de câmbio delas decorrente é mais apreciada do que deveria ser (ponto à direita da curva $\mathrm{AA}$ ). $\mathrm{O}$ sinal de mercado é inequívoco no sentido de induzir o Banco Central a reduzir a taxa de juros. O processo de aproximações sucessivas converge para o encontro das curvas AA e BB.

No ramo anômalo, o desempenho da norma de atuação do Banco Central depende da situação inicial. Se a taxa de juros inicial for menor do que $\mathrm{R}_{2}$, o Banco Central se defrontará com uma inflação necessariamente inferior à meta, porque a taxa de câmbio resultante do equilíbrio de mercado é mais apreciada do que deveria ser para gerar a inflação $\pi^{*}$. A resposta do mercado novamente o induzirá a reduzir a taxa de juros, afastando-se ainda mais do equilíbrio ruim. E se o Banco Central não se importar com efeitos de segunda ordem (o quanto a inflação se reduz para cada ponto percentual de redução na taxa de juros), persistirá no afrouxamento da política monetária até encontrar o bom equilíbrio, pois a curva BB nos mostra que qualquer taxa de juros menor do que $R_{2}$ mas maior do que $R_{1}$ acarreta inflações acima da meta.

O oposto ocorre quando a taxa inicial de juros é maior do que $\mathrm{R}_{2}$. Diante de uma inflação maior do que a meta, a norma de atuação prescreveria aumentar os juros. Intuitiva para o senso-comum, tal norma revela-se então nefasta nas suas conseqüências, posto que o Banco Central deveria reduzir os juros para assegurar a meta e não aumentá-los.

A dinâmica no ramo anômalo é assim divergente. O equilíbrio ruim, ao contrário do bom, é instável. Somente representará um equilíbrio no sentido usual do termo (ausência de incentivo para mudança) se, por acidente ou ironia da história, o Banco Central nele se enclausurar diretamente, prescindindo de qualquer tâtonnement. O leitor talvez possa entreter-se, na ausência de melhor alternativa, construindo um equilíbrio estável no ramo anômalo da curva BB. (Dica: a curva AA deve cortar BB vinda de baixo).

\section{TAXA DE JUROS EXTERNA, POLÍTICA FISCAL, RISCO SOBERANO ECONVERSIBILIDADE}

O objetivo desta seção é discutir o efeito de alterações em variáveis fora da alçada do Banco Central. Para simplificar, a economia se encontra no bom equilíbrio antes das mudanças aqui consideradas; o leitor ganhará entendimento sobre situações aparentemente paradoxais refazendo a análise para outros equilíbrio ruins, estáveis ou não.

Considere inicialmente um aumento na taxa de juros pelo Federal Reserve. Veja em (2) que para a mesma taxa de juros a arbitragem no mercado de ativos requer câmbio mais depreciado. No gráfico II a curva pontilhada reflete a curva BB antes do aumento da taxa de juros externa e a curva cheia reflete a curva após o aumento. $\mathrm{O}$ Banco Central verifica que à taxa $\mathrm{R}_{1}$ a inflação é maior do que $\pi^{*}$. Para manter a 
inflação em linha com a meta deve acompanhar em algum grau a política contracionista do Federal Reserve, subindo a taxa de juros doméstica até $\mathrm{R}_{3}$.

Considere a seguir um anúncio crível de uma política fiscal mais contracionista (maior $\Theta$ e portanto menor risco de default para qualquer taxa de juros fixada pelo Banco Central). O leitor poderá verificar que a expectativa de um choque fiscal corresponde, graficamente, a um deslocamento para fora da curva BB, levando a uma redução na taxa de juros e apreciando o câmbio para a mesma meta inflacionária.

Considere agora o efeito de variações exógenas no risco soberano, entendido como a probabilidade de default atribuída aos títulos da dívida externa. Para analisálo é preciso introduzir no modelo o endividamento externo. No nosso caso, os títulos da dívida externa tem perfil mais alongado do que os da dívida interna e a arbitragem se faz portanto com títulos da dívida emitida pelo Tesouro Norte-Americano de prazo mais longo. Clareza de pensamento, no entanto, pode ser conseguida abstraindo as questões da estrutura a termo e caracterizando o título da dívida externa como uma nota fixa (cupom zero). Diante destas hipóteses simplificadoras, a arbitragem entre um real (ou um dólar) investido em um título de dívida externa emitido pelo Tesouro Brasileiro e um título emitido pelo Tesouro Norte-Americano é dada por (4) abaixo:

$$
\left(1+\mathrm{R}^{\mathrm{m}}\right) \cdot(1-\delta)=\left(1+\mathrm{R}^{\mathrm{US}}\right)
$$

Em (4), $\mathrm{R}^{\mathrm{m}}$ é a rentabilidade de mercado paga nos títulos da dívida externa e $\delta$ é o risco soberano. Evidentemente (4) supõe igualmente neutralidade em relação ao risco e caracteriza o risco soberano como um risco default do tipo tudo ou nada. Na presença de dívida externa, (4) e (2) tipificam a arbitragem de ativos, sendo $\mathrm{R}^{\mathrm{m}}$ a variável residual de ajuste. ${ }^{3}$

O risco soberano $\delta$ reflete em parte fatores estritamente internos do país. Reflete também fatores exógenos como contaminação por crises enfrentadas por outros países emergentes, mudanças na percepção de risco como um todo, emanadas do núcleo central, importância estratégica do país no contexto de relações internacionais, etc. Para analisar com máxima simplicidade o efeito de choques exógenos, considere o caso limite em que o risco soberano independe de fatores internos. $\mathrm{Ou}$ seja, $\delta$ é um parâmetro dado para o Banco Central. É trivial observar então, por arbitragem entre (4) e (2), que uma deterioração no risco soberano (maior $\delta$ ) funciona de forma idêntica a um aumento na taxa de juros fixada pelo Federal Reserve, exigindo uma taxa de juros em reais mais elevada para manter a mesma inflação.

Por último, considere o efeito da introdução de restrições à conversibilidade. A equação (2) supõe que a moeda nacional é plenamente conversível, ou seja, inexiste qualquer forma de controle de saída de capitais. Controles de capital fazem com que a taxa de câmbio que equilibra oferta e demanda no mercado de moeda estrangeira penalize aqueles que optaram por manter sua riqueza em moeda do-

\footnotetext{
${ }^{3} \mathrm{O}$ passado, não necessariamente um bom guia para o futuro, sugere que $\delta>\lambda(\mathrm{R})$ para todo e qualquer $\mathrm{R}$.
} 
méstica. Seja p a probabilidade subjetiva de imposição de controle de capitais no final do período, tal como percebida no início do período, e $\mathrm{k}$ seu custo estimado (reflexo do ágio no mercado livre). A equação (2) modifica-se então para:

$$
\left.(1+\mathrm{R}) \cdot(1-\lambda)=\left(1+\mathrm{R}^{\mathrm{US}}\right) \cdot \mathrm{E} \cdot[(1-\mathrm{p})+\mathrm{p} \cdot \mathrm{k})\right]
$$

Deixo ao leitor o estudo de variações em $\mathrm{p}$. (Dica para interpretação: um valor maior de $\mathrm{p}$ equivale à expectativa de um valor maior da taxa de câmbio que prevalecerá ao final do período).

\section{OBSERVAÇÃO FINAL}

O modelo (1)-(3) é um modelo de curto prazo. A arbitragem entre ativos em (2) supõe que no final do período a taxa de câmbio retornará ao seu valor de longo prazo. Ora, a hipótese de retorno à normalidade supõe que os agentes saibam qual é o valor de longo prazo da taxa de câmbio. No modelo $Z$ (f) é uma magnitude conhecida. No mundo real, $Z(f)$ é o resultado de um processo que cria conforto recíproco entre os agentes validando socialmente determinadas convenções sobre como o futuro se dará. Isto nos remete ao tópico da terceira nota da série.

\section{APÊNDICE}

Para exemplificar casos nos quais pode-se tratar a taxa real de juros como variável de política monetária é útil retomar o modelo apresentado na primeira nota desta série. Trata-se de modelo formulado para uma economia fechada, consistindo nas equações (1.1) e (1.2) abaixo.

(1.1) é uma curva de Phillips linearizada com inércia. Em (1), y é o hiato doproduto (isto é, a diferença entre o produto observado e o produto natural que resultaria de irrestrita flexibilidade nominal de preços) e $\varepsilon$ uma variável aleatória que captura choques de oferta. O coeficiente $\alpha>0$ capta o efeito da demanda sobre a inflação.

$$
\pi=\pi_{-1}+\alpha \cdot y+\varepsilon
$$

(1.2) é uma demanda agregada também especificada de forma linear e semcorrelação serial. Em (2), i é a taxa nominal de juros, E $\pi$ é a inflação esperada pelos agentes, $r^{*}$ é a taxa real neutra de juros (isto é, a taxa real de juros que resultaria da irrestrita flexibilidade nominal de preços) e $\eta$ a variável aleatória que captura choques de demanda. O coeficiente $\beta$ é positivo; a política monetária só influencia o produto quando a taxa de real de juros ex-ante, dada por [i - E $\pi]$, difere da taxa neutra que levaria o produto a coincidir com o seu nível natural. Quanto maior a taxa ex-ante de juros, menor a demanda agregada.

$$
y=-\beta \cdot\left[i-E \pi-r^{*}\right]+\eta
$$


No modelo da primeira nota, as variáveis aleatórias são distribuídas de modo independente e idêntico, média zero e variância finita. Nesta nota, ignoram-se choques de oferta e demanda, ou seja, $\varepsilon=\eta=0$. Substituindo (1.2) em (1.1) e definindo R como a taxa real de juros ex-ante, obtemos (1.3):

$$
\pi=\text { constante }-\alpha \cdot \beta \cdot R
$$

onde constante $=\pi_{-1}+\alpha \cdot \beta \cdot r^{*}$. A função (1.3) é uma forma linear de (1).

$\operatorname{Em}(1.3), \mathrm{R}=[\mathrm{i}-\mathrm{E} \pi]$. Variações na taxa nominal só se traduzirão em variações pari passu na taxa real se as expectativas forem a elas invariantes. Isto ocorre, por exemplo, com expectativas adaptativas: $\mathrm{E} \pi=\pi_{-1}$. Ocorre também quando o anúncio da meta inflacionária é recebido com credibilidade integral: $\mathrm{E} \pi=\pi^{*}$. Ocorre igualmente quando os agentes desconfiam parcialmente da determinação do Banco Central em fazer cumprir a meta quando a meta envolver uma contração no produto. Um exemplo é dado pela regra (1.4) abaixo.

$$
\mathrm{E} \pi=\pi^{*} \text { se } \pi^{*} \geq \pi_{-1}, \mathrm{E} \pi=\mathrm{a} \cdot \pi^{*}+(1-\mathrm{a}) \cdot \pi_{-1} \text { se } \pi^{*}<\pi, 0<\mathrm{a}<1
$$

Em geral, qualquer regra de formação de expectativas que determine $E \pi$ de modo autônomo à taxa nominal de juros é suficiente para que se possa tratar $\mathrm{R}$ como se fosse uma variável de política.

\section{GRÁFICOS}

Gráfico I

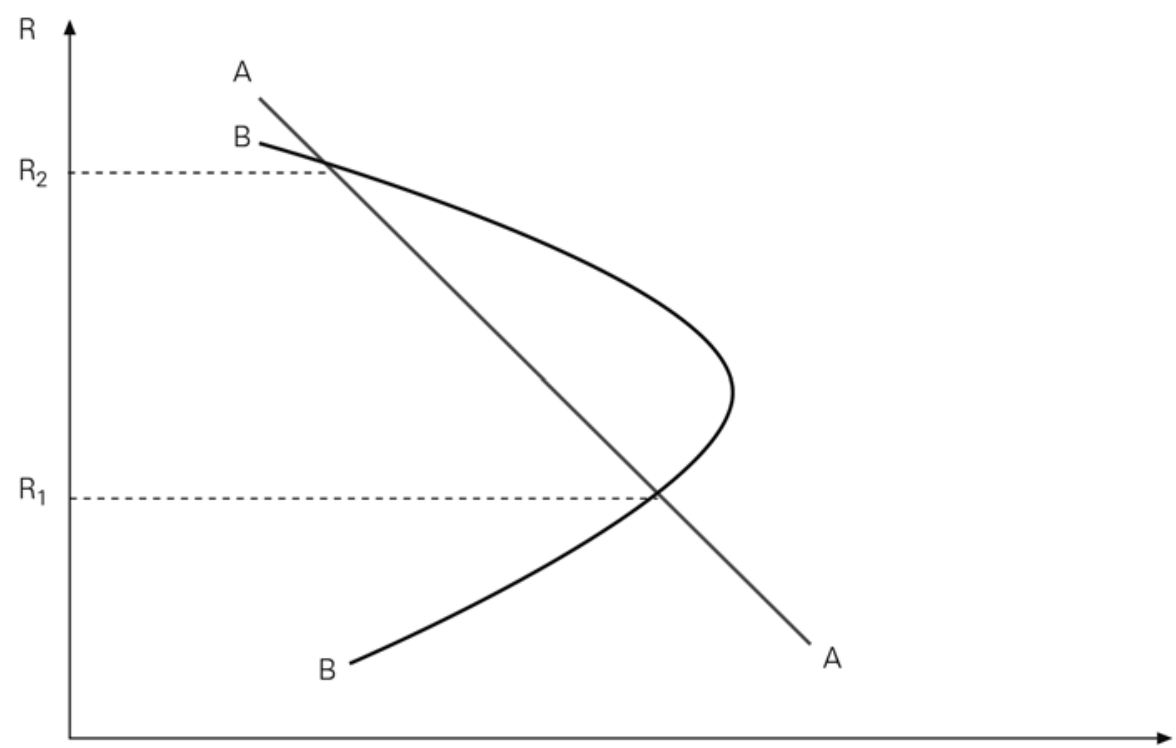


Gráfico II

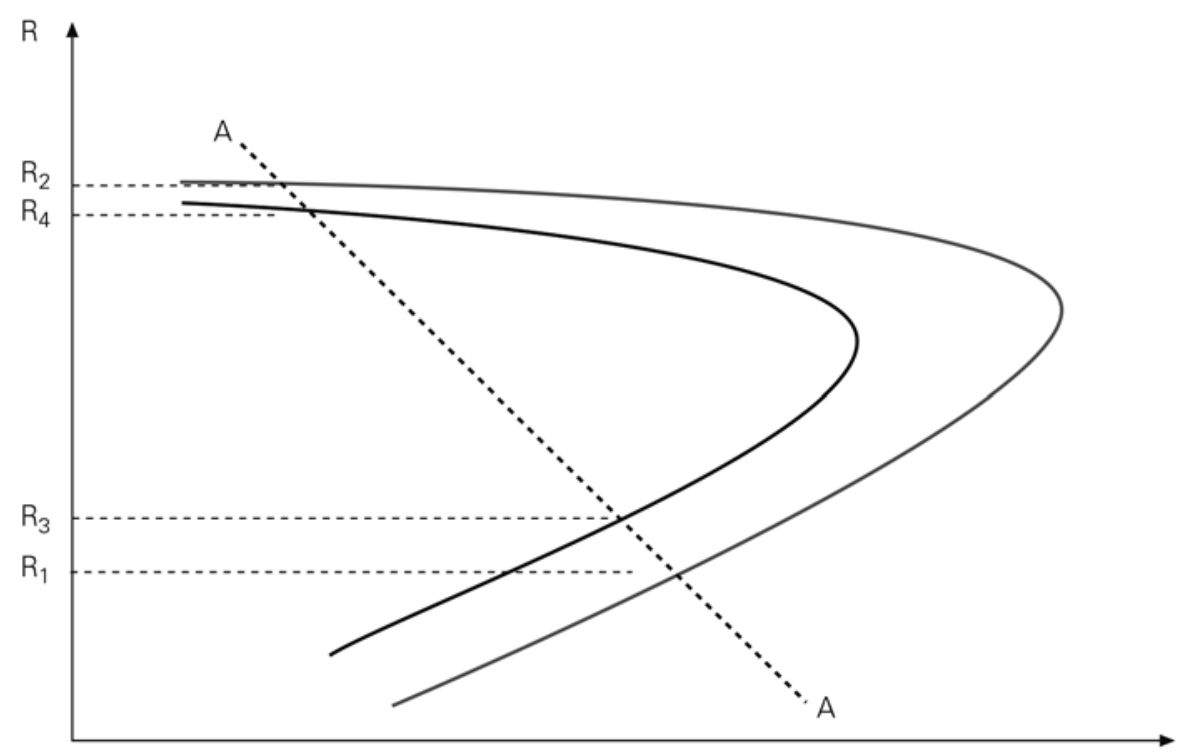

